\title{
Interprofessional Communication Patterns During Patient Discharges: A Social Network Analysis
}

\author{
Vincent A. Pinelli, DO, Klara K. Papp, PhD, and Jed D. Gonzalo, MD, MSc
}

Pennsylvania State University College of Medicine, Hershey, PA, USA.

BACKGROUND: Optimal care delivery requires timely, efficient, and accurate communication among numerous providers and their patients, especially during hospital discharge. Little is known about communication patterns during this process.

OBJECTIVE: Our aim was to assess the frequency and patterns of communication between patients and providers during patient discharges from a hospital-based medicine unit.

DESIGN AND APPROACH: On the day of the patient's discharge, the patient and all healthcare providers involved in the discharge were interviewed using structured questions related to information exchange during the discharge process. Each interview identified the frequency and method of communication between participants, including synchronous (e.g., face-to-face) and asynchronous (e.g., through electronic medical record) routes. Communication patterns were visually diagramed using social network analysis.

PARTICIPANTS: Forty-six patients were screened for inclusion in the network analysis. Of those, seven patients who were fully oriented and able to complete an interview and all providers who participated in their care during the discharge were selected for inclusion in the analysis. In all, 72 healthcare professionals contributing to the discharge process were interviewed, including physicians, nurses, therapists, pharmacists, care coordinators, social workers, and nutritionists.

KEY RESULTS: Patients' mean age was 63, length-ofstay was 7.8 days, and most (86\%) were discharged to home. On average, 11 roles were involved with each discharge. The majority of communication was synchronous (562 events vs. 469 asynchronous events, $p=0.004$ ). Most communication events occurred between the primary nurse and patient and the care coordinator and primary nurse (mean 3.9 and 2.3 events/discharge, respectively). Participants identified intern physicians as most important in the discharge process, followed by primary nurses and care coordinators.

CONCLUSIONS: In patients being discharged from the medicine service, communication was more frequently synchronous, and occurred between intern physicians, primary nurses, and patients. Potential improvements in coordinating patients' discharges are possible by reorganizing systems to optimize efficient communication.

Electronic supplementary material The online version of this article (doi:10.1007/s11606-015-3415-2) contains supplementary material, which is available to authorized users.

Published online July 15, 2015
J Gen Intern Med 30(9):1299-306 DOI: $10.1007 / \mathrm{s} 11606-015-3415-2$

(c) Society of General Internal Medicine 2015

\section{BACKGROUND}

Transitions of care from hospital-based units to outpatient settings are often accompanied by adverse events, medical errors, and readmissions. ${ }^{1-5}$ Policies and hospital-based strategies to improve the quality of discharge care following a patient's admission and discharge from the hospital have been implemented. ${ }^{1,6-8}$ Transitions of care initiatives, such as the Better Outcomes for Older Adults through Safe Transitions, and quality collaboratives, such as the State Action on Avoidable Rehospitalization initiative, provide approaches and strategies at the unit level to improve this process. ${ }^{9-11}$ A prerequisite for these initiatives, however, is high-quality communication and collaboration between the myriad of providers and patient involved in the discharge process.

In hospital-based medicine units, patient discharges can be complicated, as patients often have several chronic comorbidities, complex transitional care plans, and potentially poor understanding of medical issues. ${ }^{12}$ Additionally, numerous providers are integral to coordinate the process, requiring significant information exchange and interdependent work for optimal care delivery. ${ }^{13,14}$ The discharge process is complex with several vulnerable areas that could potentially lead to poor outcomes - communication is a critical component in this process. Poor communication and inadequate collaboration during discharges result in inefficient care and preventable medical errors. ${ }^{15,16}$ Although studies have investigated perceptions and best practices regarding discharges, to our knowledge, no studies have described the complexity involved in communication channels amongst the many providers involved in this process. With recommendations to improve care models in "health literate" organizations, the success of new initiatives related to collaboration and health information technology, relies, in part, on well-developed communication networks between providers during patient discharges. ${ }^{17-22}$

Although the ideal discharge process involves collaboration amongst care providers, existing research provides a relatively poor understanding of how professionals communicate in medicine units during discharges. We sought to advance the field by studying the extent to which communication and collaboration occur during a patient's discharge from the 
medicine service and which individuals are central and peripheral to the process. ${ }^{23}$ In this study using social network analysis, we sought to assess: (1) the frequency and type of communication patterns between providers and patients, and, (2) the network of communication patterns between providers and patients during the discharge process.

\section{METHODS}

\section{Study Design}

To investigate communication between patients and providers during discharges, we applied methods of social network analysis (SNA). ${ }^{24,25}$ The study sample included seven patients discharged from the medicine service and all front-line providers involved with each patient discharge (range 11-14 per discharge). The Penn State University Institutional Review Board approved this study as a quality improvement project and not as human subjects research.

\section{Social Network Approach}

We used the theoretical perspective of SNA to conceptualize the social structure of the discharge process. ${ }^{25,26} \mathrm{We}$ chose this method because of the limitations and infeasibility of surveys and observations, and because these methods focus upon individuals and their relationships. SNA is designed to depict the linkages between individuals, or the "relational systems of individuals," within complex environments. ${ }^{27}$ Any one individual has a limited view of the complex network in which they are involved. Illustrating interactions in the communication network allows for the identification of improvement areas and considerations into advancing discharge planning research and theory. In applying this approach, we were primarily interested in the quantity and type of communication exchanges between providers.

The structure of the network includes consideration of its size (i.e., how many types of providers are involved?). The density of the network is expressed as the total number of interactions that occurred within the network over the total possible number of interactions. The strength of the ties between two points may be visualized by the width of the line, which represents the frequency of interactions between two points. Thus, compared to narrow lines, wide lines demonstrate more frequent interactions between two points. The position of each point in the network is drawn to minimize the number of intersecting lines. Therefore, points with the highest number of lines are depicted in the center and reflect high betweenness centrality. Betweenness centrality counts the number of shortest paths between each member of the network. A position with high betweenness centrality can reach any individual in the network more easily given their connections when compared to positions with low betweenness centrality scores. A person situated on communication paths can control communication flow, and is thus important. ${ }^{28}$

\section{Study Setting}

The study was conducted at a 501-bed university-based, acutecare teaching hospital, with 64 internal medicine beds in a general medicine unit (44 beds, 60 nurses) and intermediate care unit ( 20 beds, 41 nurses). Five teams, organized into three teaching teams and two non-teaching teams, provide care for all patients. ${ }^{29}$ The internal medicine residency program consists of 69 medicine and 14 medicine-pediatrics house staff. Teaching teams consist of one junior (PGY2) or senior (PGY3-4) house staff, two interns (PGY1), $\leq 2$ medical students, and one attending physician. Care coordination rounds occur each morning for each team (15 min apiece), and are led by resident physicians, care coordinator, and charge nurse.

\section{Participants and Screening Process}

In March 2014, one investigator (V.P.) screened a convenience sample of patients during 7 days by observing care coordination rounds, reviewing the electronic medical record (EMR), and discussing with medicine teams. Inclusion criteria for patient selection included: (1) anticipated discharge on that day, and (2) patient was oriented and able to complete a face-to-face interview. We sought to include a broad sampling of patients, with typical medical diagnoses and $>50 \%$ including consultation services and higher levels of care during hospitalization. Earlier discharge times were preferred to allow for interviews to be completed prior to endof-day shifts. A real-time log was kept to record data about screened patients (Table 1). For each study day, one patient was chosen for analysis. To identify all potential providers in the network, in addition to EMR review, a chain-sampling technique was used whereby providers known to be involved (e.g., nurse) were interviewed and asked to identify other providers with whom they communicated during the

Table 1. Characteristics of Patients Screened $(n=46)$ for Inclusion in Network Analyses Regarding Patient Discharges from the Medicine Service

\begin{tabular}{ll}
\hline \hline Item & Total - n (\%) \\
\hline Age (years) - mean & 67.2 \\
Gender (female) & $25(54)$ \\
Length of stay (days) & 7.84 \\
Disposition to home (yes) & $28(61)$ \\
Patient able to complete interview (yes) & $33(72)$ \\
Providers Involved within 24 h of discharge: & \\
Intern & $46(100)$ \\
Junior/Senior resident & $46(100)$ \\
Attending physician & $46(100)$ \\
Primary nurse & $46(100)$ \\
Charge nurse & $46(100)$ \\
Care coordinator & $46(100)$ \\
Pharmacist & $45(98)$ \\
Consulting service attending & $30(65)$ \\
Physical therapist & $29(63)$ \\
Occupational therapist & $27(59)$ \\
Social worker & $27(59)$ \\
Nutritionist & $26(57)$ \\
Consulting service fellow & $24(52)$ \\
Medical student & $5(11)$ \\
\hline
\end{tabular}


discharge. ${ }^{30}$ For example, if an intern physician reported communicating with a pharmacist, that individual was then contacted. In nearly all cases ( $>95 \%$ ), all providers were identified through EMR review alone.

\section{Survey Instrument}

The SNA survey was developed for the purposes of this study, pilot-tested with two attending physicians, and subsequently modified to improve clarity (Appendix 1). After framing the interview around a specific patient, respondents were asked to report the following synchronous and asynchronous communication events within $24 \mathrm{~h}$ of discharge: (1) how often they communicated about the discharge with individuals in the network (to consider all methods of synchronous communication: face-to-face, phone calls, paging), (2) how often they relied on asynchronous communication in the EMR from individuals to be informed about discharge plans, and, (3) importance of that role in enabling the discharge (Likert scale 1-7, 1=not at all important, 7=extremely important). Respondents were asked how many times he/she input information into the discharge instructions and summary.

\section{Data Collection}

During 7 days and starting with the soon-to-be discharged patient, one investigator (V.P.) performed 1:1 structured interviews with patients and providers involved in the discharge process. Participants were contacted via page, telephone, or identified in person to answer questions with investigator facilitation. If any provider could not be immediately contacted, the survey was emailed promptly after the discharge, with a follow-up phone call/page the next morning requesting completion.

\section{Analysis and Outcomes}

Frequencies and comparison of communication (synchronous/ asynchronous) and perceived importance of each role were analyzed using descriptive statistics and chi-square test. NodeXL Graphics software (Version:1.0.1.326) was used to construct sociograms of communication channels related to patients' discharges. ${ }^{24}$

\section{RESULTS}

\section{Screened Patients}

A total of 46 patients were screened to undergo a network analysis (mean age 67). Sixty-one percent (61\%) were discharged to their prior location, and $72 \%$ were sufficiently oriented to complete an interview. For all patients, six provider roles were involved in the process: intern, resident, and attending physicians, primary nurse, charge nurse, and care coordinator (Table 1).

\section{Network Analysis}

Seven patients were analyzed using network analysis, with a mean age of 63 , length of stay of 7.8 days, and $6 / 7$ (86\%) were discharged to home (Table 2). Seventy-nine providers and patients were involved in seven discharges (mean 11.3 per discharge). From these seven discharges, 67 interviews and five emailed surveys were completed by participants $(n=72$, $100 \%$ response).

\section{Frequency and Type of Communication}

The majority of communication was synchronous rather than asynchronous (562 vs. 469 total events, $p=0.004$ ). Most frequent channels of communication occurred between the primary nurse and patient (mean 3.9 verbal communication events per discharge). House staff physicians commonly communicated with each other, with resident and intern physicians averaging three communication events between them during discharges (Table 3).

\section{Perceived Importance of Roles in the Discharge Process}

In relation to perceived importance of participant role in enabling patients' discharges, the intern physician role was identified as most important (mean 6.03, potential maximum=7), with the primary nurse (5.34) and care coordinator (5.32) rated next in importance (Table 4).

\section{Frequency of Contributions to Discharge Instructions and Summaries}

The intern physician role was the most likely to contribute to discharge instructions and summary (3.0 and 2.0 contributions, respectively_Appendix 2). Five other roles contributed to discharge instructions, with the social worker role as the second-highest contributor (mean 0.57 contributions).

\section{Network Diagrams}

Figure 1 depicts the combined frequency of communication amongst providers and patients occurring within $24 \mathrm{~h}$ of the seven discharges. This network has a density of 0.625 ; if each of 16 members of the network communicated with every other member in the network, there would be a total of $16 \times 16=256$ lines representing communication within and between roles. This network has 160/256 lines, suggesting a relatively dense network. Central to the network, with close ties to the patient, are the intern physician and primary nurse. Attending physicians, charge nurses, and social workers had fewer interactions, on average, with patients during discharges.

Figure 2a depicts synchronous (i.e., real-time communication) and Fig. 2b depicts asynchronous (i.e., communication through EMR). Primary team members, including intern, resident, and attending physicians appear to have high 
Table 2. Characteristics of Networks for Patients Included in Analysis ( $n=7)$ Regarding Communication During Discharge from the Medicine Service

\begin{tabular}{|c|c|c|c|c|c|c|c|c|}
\hline \multirow[b]{2}{*}{ Item } & \multicolumn{7}{|c|}{${\text { Patients Assessed with Network Analysis }(n=7)^{a}}^{a}$} & \multirow[b]{2}{*}{$\begin{array}{l}\text { Total - n } \\
(\%)\end{array}$} \\
\hline & 1 & 2 & 3 & 4 & 5 & 6 & 7 & \\
\hline Diagnoses & $\begin{array}{l}\text { Septic } \\
\text { shock, } \\
\text { fungemia, } \\
\text { pneumonia }\end{array}$ & $\begin{array}{l}\text { Arrhythmia, } \\
\text { heart block, } \\
\text { hyperkalemia }\end{array}$ & $\begin{array}{l}\text { Pulmonary } \\
\text { embolism, } \\
\text { DVT }\end{array}$ & $\begin{array}{l}\text { Diastolic } \\
\text { CHF, } \\
\text { septic } \\
\text { shock, } \\
\text { pneumonia }\end{array}$ & $\begin{array}{l}\text { Acute } \\
\text { kidney } \\
\text { injury } 2 / 2 \\
\text { diarrhea }\end{array}$ & $\begin{array}{l}\text { Sepsis } 2 / 2 \\
\text { cellulitis/c-diff } \\
\text { colitis }\end{array}$ & $\begin{array}{l}\text { Cellulitis, } \\
\text { venous } \\
\text { insuff, } \\
\text { ulceration }\end{array}$ & \\
\hline Age (years) & 76 & 52 & 67 & 71 & 85 & 34 & 56 & 63 \\
\hline Gender (female) & $\mathrm{Y}$ & $\mathrm{Y}$ & $\mathrm{Y}$ & - & - & - & $\mathrm{Y}$ & $4(57)$ \\
\hline Length of stay (days) & 14.0 & 4.5 & 1.6 & 6.0 & 11.9 & 12.9 & 4.0 & 7.81 \\
\hline $\begin{array}{l}\text { Intermediate/intensive } \\
\text { care (at any point) }\end{array}$ & $\mathrm{Y}$ & - & - & $\mathrm{Y}$ & $\mathrm{Y}$ & $\mathrm{Y}$ & - & $4(57)$ \\
\hline Disposition to home (yes) & - & $\mathrm{Y}$ & $\mathrm{Y}$ & $\mathrm{Y}$ & $\mathrm{Y}$ & $\mathrm{Y}$ & $\mathrm{Y}$ & $6(86)$ \\
\hline $\begin{array}{l}\text { Patient able to complete } \\
\text { interview (yes) }\end{array}$ & $\mathrm{Y}$ & $\mathrm{Y}$ & $\mathrm{Y}$ & $\mathrm{Y}$ & $\mathrm{Y}$ & $\mathrm{Y}$ & $\mathrm{Y}$ & $7(100)$ \\
\hline \multicolumn{9}{|c|}{ Providers involved $<24 \mathrm{~h}$ of discharge: } \\
\hline Intern physician & Y & $\mathrm{Y}$ & $\mathrm{Y}$ & $\mathrm{Y}$ & $\mathrm{Y}$ & Y & $\mathrm{Y}$ & $7(100)$ \\
\hline $\begin{array}{l}\text { Junior/senior resident } \\
\text { physician }\end{array}$ & Y & $\mathrm{Y}$ & $\mathrm{Y}$ & $\mathrm{Y}$ & $\mathrm{Y}$ & $\mathrm{Y}$ & $\mathrm{Y}$ & $7(100)$ \\
\hline Attending physician & $\mathrm{Y}$ & $\mathrm{Y}$ & $\mathrm{Y}$ & $\mathrm{Y}$ & $\mathrm{Y}$ & $\mathrm{Y}$ & $\mathrm{Y}$ & $7(100)$ \\
\hline Primary nurse & $\mathrm{Y}$ & $\mathrm{Y}$ & $\mathrm{Y}$ & $\mathrm{Y}$ & $\mathrm{Y}$ & $\mathrm{Y}$ & $\mathrm{Y}$ & $7(100)$ \\
\hline Charge nurse & $\mathrm{Y}$ & $\mathrm{Y}$ & $\mathrm{Y}$ & $\mathrm{Y}$ & $\mathrm{Y}$ & $\mathrm{Y}$ & $\mathrm{Y}$ & $7(100)$ \\
\hline Care coordinator & $\mathrm{Y}$ & $\mathrm{Y}$ & $\mathrm{Y}$ & $\mathrm{Y}$ & $\mathrm{Y}$ & $\mathrm{Y}$ & $\mathrm{Y}$ & $7(100)$ \\
\hline Pharmacist & - & $\mathrm{Y}$ & $\mathrm{Y}$ & $\mathrm{Y}$ & $\mathrm{Y}$ & $\mathrm{Y}$ & $\mathrm{Y}$ & $6(86)$ \\
\hline Social worker & $\mathrm{Y}$ & - & $\mathrm{Y}$ & $\mathrm{Y}$ & $\mathrm{Y}$ & - & $\mathrm{Y}$ & $5(71)$ \\
\hline Consulting service & $\mathrm{Y}$ & $\mathrm{Y}$ & $\mathrm{Y}$ & - & - & - & $\mathrm{Y}$ & $4(57)$ \\
\hline attending physician & & & & & & & & \\
\hline $\begin{array}{l}\text { Consulting service } \\
\text { fellow physician }\end{array}$ & $\mathrm{Y}$ & $\mathrm{Y}$ & - & - & - & - & $\mathrm{Y}$ & $3(43)$ \\
\hline Nutritionist & $\mathrm{Y}$ & - & - & - & - & $\mathrm{Y}$ & $\mathrm{Y}$ & $3(43)$ \\
\hline Occupational therapist & - & $\mathrm{Y}$ & $\mathrm{Y}$ & $\mathrm{Y}$ & - & - & - & $3(43)$ \\
\hline Physical therapist & - & - & $\mathrm{Y}$ & $\mathrm{Y}$ & - & $\mathrm{Y}$ & - & $3(43)$ \\
\hline Consult resident & - & - & $\mathrm{Y}$ & - & - & - & $\mathrm{Y}$ & $2(29)$ \\
\hline physician & & & & & & & & \\
\hline Medical student & - & - & - & - & $\mathrm{Y}$ & - & - & $1(14)$ \\
\hline
\end{tabular}

a " $Y$ " stands for "yes," indicating an affirmative response to each item

$D V T=$ deep vein thrombosis, $C H F=$ congestive heart failure, $C$-diff=clostridium difficile, venous insuff=venous insufficiency

betweenness centrality scores, i.e., they are at the center of the network. Consulting services (attending/fellow physicians), nutritionists, therapists, and pharmacists are in the periphery. Figure 1 is substantially different when synchronous and asynchronous communications are partialled out (Fig. 2a-b).
Figure 2 visually displays communications among providers listed in Table 3. It is best understood when comparing two sets of providers in A/B. For example, the 'charge nurse' and 'nurse' have many more synchronous communication events than do asynchronous ones.

Table 3. Frequency of Communication Events and Most Common Frequency Relationships Amongst Providers or Patients ( $n=7$ ) Occurring Within 24 h of Discharge for Patients Discharged from the Medicine Service

\begin{tabular}{|c|c|c|c|c|}
\hline Category of communication & $\begin{array}{l}\text { No. communication events } \\
\text { (ave./patient discharge) }\end{array}$ & Initiator & Recipient & $\begin{array}{l}\text { Mean no. events } \\
\text { per discharge }\end{array}$ \\
\hline \multirow[t]{8}{*}{ Synchronous (face-to-face, phone calls, paging) } & \multirow[t]{8}{*}{$562(80.30)$} & Primary nurse & Patient & 3.90 \\
\hline & & Resident physician & Intern physician & 3.00 \\
\hline & & Intern physician & Patient & 2.71 \\
\hline & & Intern physician & Resident physician & 2.71 \\
\hline & & Intern physician & Primary nurse & 2.71 \\
\hline & & Patient & Primary nurse & 2.57 \\
\hline & & Attending physician & Intern physician & 2.57 \\
\hline & & Attending physician & Resident physician & 2.57 \\
\hline \multirow[t]{7}{*}{ Asynchronous (reading electronic medical record) } & \multirow[t]{7}{*}{$469(67.00)$} & Care Coordinator & Primary nurse & 2.29 \\
\hline & & Intern physician & Primary nurse & 2.00 \\
\hline & & Attending physician & Intern physician & 2.00 \\
\hline & & Intern physician & Care Coordinator & 1.86 \\
\hline & & Intern physician & Attending physician & 1.71 \\
\hline & & Resident physician & Primary nurse & 1.71 \\
\hline & & Resident physician & Intern physician & 1.57 \\
\hline
\end{tabular}


Table 4. Reported Importance of Provider's Roles in Enabling a Patient's Discharge from the Medicine Service $(n=79)$

\begin{tabular}{lcc}
\hline \hline Provider & $\begin{array}{l}\text { No. responses } \\
\text { submitted by } \\
\text { provider role }\end{array}$ & Mean rating $^{\mathbf{b}}$ \\
\hline Intern physician & 7 & 6.03 \\
Primary nurse & 7 & 5.34 \\
Care coordinator & 7 & 5.32 \\
Social worker & 5 & 5.15 \\
Resident physician & 7 & 5.05 \\
Attending physician & 7 & 4.88 \\
Consult resident physician & 2 & 4.67 \\
Consult attending physician & 4 & 4.47 \\
Consult fellow physician & 3 & 4.35 \\
Physical therapist & 3 & 4.22 \\
Occupational therapist & 3 & 3.48 \\
Medical student & 1 & 3.40 \\
Pharmacist & 6 & 3.35 \\
Charge nurse & 7 & 2.79 \\
Nutritionist & 3 & 2.36 \\
\hline
\end{tabular}

${ }^{a}$ Each role interviewed for the SNA was asked the "importance" question of all other roles with whom they communicated. As reflected in Table 2, the response rate was $100 \%$; seven patients additionally answered this question for all provider roles in his/her discharge process (for a total of 79 responses)

${ }^{b}$ Likert-scale questions with $1=$ Not at all important, $7=$ Extremely important

\section{DISCUSSION}

Communication during patient discharges from our medicine service involves a significant number of providers, using both synchronous and asynchronous methods, and with a high frequency of communication events. Notably, the primary nurse and the intern physician, who is also the most inexperienced provider in the network, have central roles in the discharge process. These data advance the limited literature about communication amongst providers and patients in the discharge process.

This descriptive study of discharge communication events and patterns is applicable and timely for several reasons. Strategies to increase interprofessional collaborative care (IPCC), the process during which providers work together to improve healthcare quality, are both a national health policy focus and common thread in the Affordable Care Act. ${ }^{31,32}$ Team-based care delivery with providers of different disciplines functioning interdependently enhances communication, coordination, and patient-centered shared-decision making. ${ }^{33-}$ ${ }^{36}$ Medicine patients have a myriad of medical, behavioral, and social issues, and as a result, the team of providers is amorphous and dynamic, and must coordinate numerous complex issues for safe transitions. ${ }^{37}$ For these reasons, IPCC that integrates tasks and allows for coordinated collective action during discharge processes, which are full of uncertainty and time constraints, can be challenging. As defined by Gittell, key components of relational coordination, including shared goals, shared knowledge, and mutual respect, all while communicating in a timely, frequent, and accurate manner, must be achieved during discharges for successful transitions. ${ }^{38}$ Amidst new incentives to improve quality, although investigations into interprofessional processes have been published, little work has investigated the "cloud" of networks beyond immediate teams involved with the discharge process in

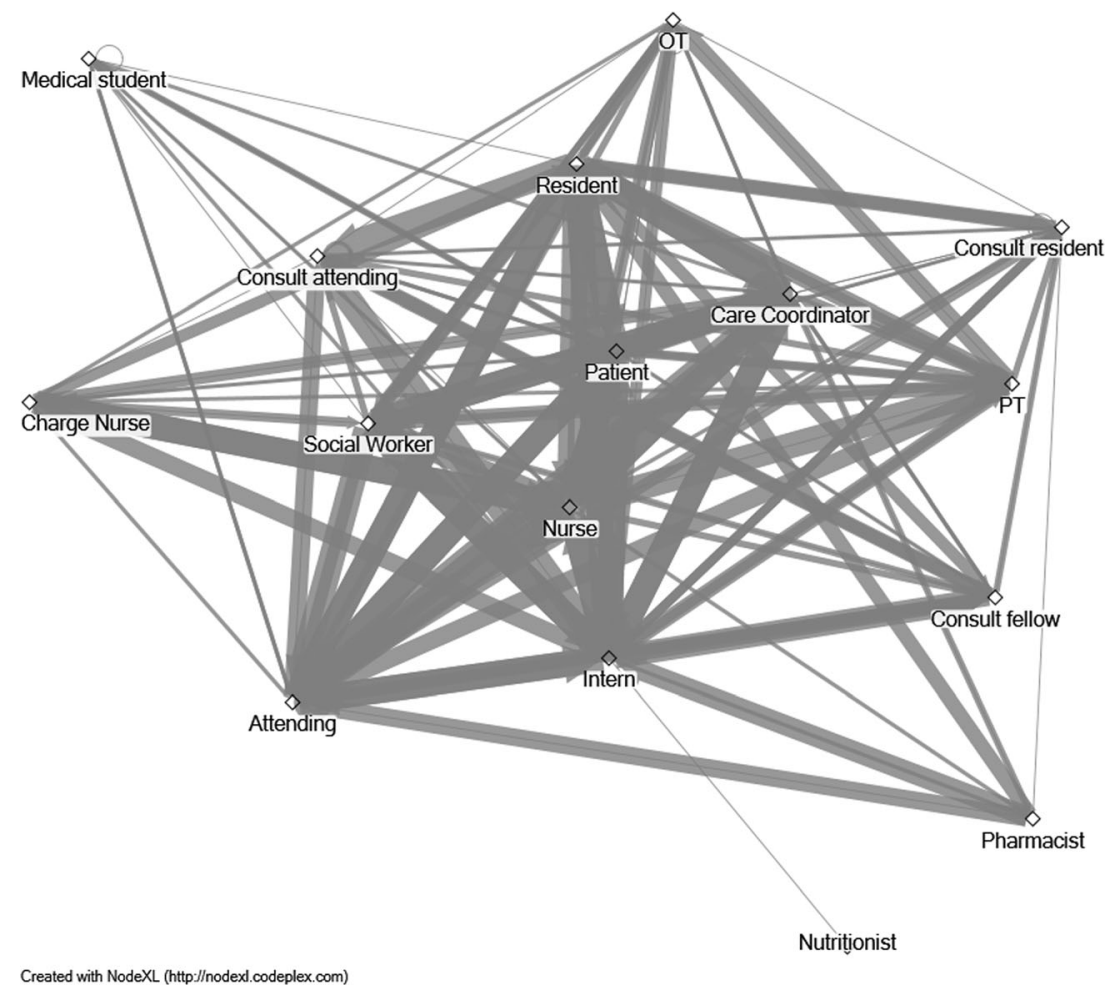

Figure 1. Social network diagram of all provider and patient communications (synchronous and asynchronous) during the discharge process from the medicine unit. All seven patient discharges and 79 interviews (seven patient interviews and 72 healthcare provider interviews) are included in this network diagram. The graph is laid out using the Fruchterman-Reingold layout algorithm. 

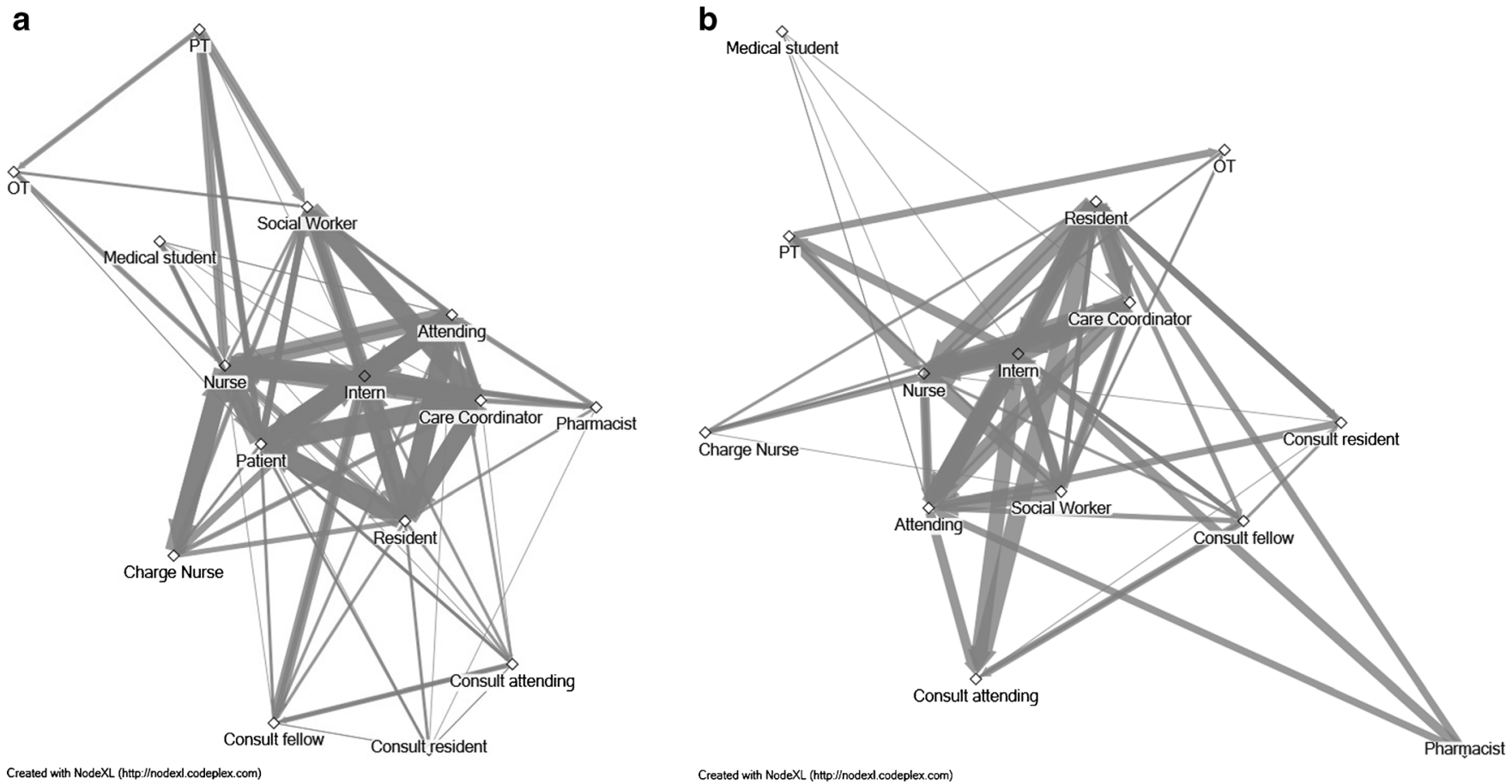

Figure 2. Social network diagrams of a synchronous communication, and $b$ asynchronous communication between providers during the discharge process from the medicine service. All interviews with healthcare providers $(n=72)$ involved in the seven patient discharges are included in these network diagrams. Patients are not included in the asynchronous communication network because they did not communicate with healthcare providers through any asynchronous methods. The graphs are laid out using the Fruchterman-Reingold layout algorithm.

academic medical centers. ${ }^{29,39,40}$ Lastly, patients' ability to obtain, process, and understand information to improve their care, or health literacy, is a cross-cutting priority area in health policy. Studies demonstrate that patients have poor understanding of medical information presented to them, resulting in unnecessary admissions and emergency department utilization. ${ }^{41}$ A "Health Literate Care Model," as described by Brach and Koh, requires optimal delivery system redesign with teambased methods and structured interactions between providers and patients, specifically during "high-risk situations, including care transitions and communications about medicines." 21,22 Although improved health literacy during transitions has potential to improve outcomes, our results highlight the complexity involved with the process and in redesigning models of teamcentered and patient-centered care, specifically with the breadth of providers involved during discharges.

Our study is limited to one academic medicine service at one hospital. Our questions pertained to communication events within $24 \mathrm{~h}$ of discharge. Respondents may have communicated with colleagues earlier in the hospitalization, in different formats or settings, or at times unidentified in our inquiry. Additionally, the discharge process may not always have a discrete start point and can be embedded in other clinical workflow not identified by respondents. Although we assessed our research questions in near-time, the timeframe reference related to $24 \mathrm{~h}$, overlapping with other shifts potentially not covered by the same individual, increasing the number of participants within the network. However, for nearly all roles, the same individual worked the day prior and could provide accurate responses. Lastly, although we included patients with varied diagnoses, exposure to higher levels of care, and a range of consultant teams, given resource limitations, we completed this study with seven patients. These patients were not fully representative of the medicine patients discharged from our service during the study period, as both the length of stay and need for intensive care are increased compared to most medicine patients, suggesting our sample may illustrate more complex networks than most patients. For these reasons, our results are not fully generalizable.

Medicine intern physicians exchanged the highest frequency of communication events, had the highest perceived importance, and were centrally located within the network, validating their pivotal role in the discharge process. In a study by Card et al., trainees were identified as playing pivotal roles during the discharge process, although these views differed between trainee and other professional groups. ${ }^{23}$ In hospitalbased medicine units, intern physicians are in a centrally positioned role during the discharge process, raising important questions about education and care delivery. For example, whether intern physicians receive adequate education and supervision with discharge activities, including coordination and documentation (e.g., instructions/summaries), is little known. ${ }^{42,43}$ More broadly, the question of whether intern physicians are the most appropriate role to be leading and coordinating discharges for complicated medicine patients merits consideration. Greysen et al. identified medicine residents' development of understanding the discharge process as they progress through training, with resident physicians 
acknowledging deficits in systems perspectives as interns and learning systems-based practice "experientially" during actual patient discharges. ${ }^{1}$ Residency programs have sought to improve education in discharge care, with recommendations to increase this issue in educational curriculum. ${ }^{1,44,45} \mathrm{We}$ acknowledge that certain components of the discharge process can be taught (e.g., components of discharge summaries), and these efforts should be pursued in residency programs, particularly during early phases of training to expedite competencies in these systems domains. However, these results may suggest that the high-stakes nature of the discharge process limits the degree of flexibility in allowing this experiential learning to occur in this complex environment. With increasing demands to optimize outcomes following discharge for such significantly ill patients, academic hospitals are faced with the challenge of balancing progressive entrustment of trainees to perform systems-based tasks (e.g., navigation of information technology, care coordination), while simultaneously achieving the best possible outcomes for each patient transition . ${ }^{42,46}$

Identification of factors enabling care coordination and teamwork during discharges from medicine units is critical for a safe transition, but are not well known. ${ }^{47,48}$ According to organization design theory, several coordinating mechanisms facilitate teamwork and IPCC, including routines (e.g., protocols, treatment pathways), individuals serving boundaryspanning roles, and team meetings, which are high-leverage for information processing and teamwork facilitation. ${ }^{38}$ Medicine house staff have variable schedules and are not longitudinal providers, limiting their ability to acquire unit-specific knowledge and skills to serve as cross-functional liaisons during discharges. Two primary methods for team meetings in medicine units are care coordination rounds and team bedside interprofessional rounds, the latter of which are infrequent. ${ }^{2,49}$ Additionally, team bedside rounds occur commonly during initial hospitalization days, rather than focusing on discharge transitions. ${ }^{29,50}$ Standardization and utility of these two interprofessional team meetings may improve communication during patient discharges.

The methods and results of this work should be considered in future scholarly initiatives. Although SNA is not specifically designed to assess the quality or content of communication patterns, this method highlights the communication patterns between individuals and the frequencies of communication exchanges. For this reason, SNA can be a valuable tool to inform needs assessments or ongoing evaluation of redesign in delivery models, specifically in medicine-based microsystems where complexity is paramount. Hospital-based units have the potential to structure workflow so healthcare providers are able to batch and streamline communication patterns to more optimally integrate synchronous communication. The potential for health information technology redesign to enhance communication and coordination during care transitions is high, decreasing reliance upon unstructured and chaotic communication channels that require additional time and energy. ${ }^{19,51}$ Although requiring time, resources, and cultural change, these methods may help minimize unnecessary and time-consuming efforts to locate providers and interruptions in workflow, thereby increasing work quality and efficiency.

In conclusion, at a large academic hospital, the process of discharging patients from the medicine service is a complex, multi-faceted process involving numerous care providers. $\mathrm{Nu}-$ merous synchronous and asynchronous methods are used amongst all providers to coordinate the patient's discharge. Intern physicians, in particular, have a pivotal role and are centrally positioned in the communication network during patient discharges, raising important questions regarding the implications of such a design, specifically related to education and the ideal model for patients' discharges.

Acknowledgements: The authors would like to thank the frontline providers in the medicine units at the Penn State Hershey Medical Center for their willingness to contribute to this work, and the Graduate Medical Education Office at the Penn State University College of Medicine for financial and resource support for this project.

Funding: This project was partly funded by an Innovation Grant from the Penn State Hershey Office of Graduate Medical Education.

Conflict of Interest: The authors declare that they do not have a conflict of interest.

Corresponding Author: Jed D. Gonzalo, MD, MSc; Pennsylvania State University College of Medicine, Hershey, PA, USA (e-mail:jgonzalo@hmc.psu.edu).

\section{REFERENCES}

1. Greysen SR, Schiliro D, Curry L, Bradley EH, Horwitz LI. "Learning by doing"-resident perspectives on developing competency in high-quality discharge care. J Gen Intern Med. 2012;27:1188-94.

2. Moore C, Wisnivesky J, Williams S, McGinn T. Medical errors related to discontinuity of care from an inpatient to an outpatient setting. J Gen Intern Med. 2003; 18:646-51.

3. Forster AJ, Murff HJ, Peterson JF, Gandhi TK, Bates DW. The incidence and severity of adverse events affecting patients after discharge from the hospital. Ann Intern Med. 2003;138:161-7.

4. Jencks SF, Williams MV, Coleman EA. Rehospitalizations among patients in the Medicare fee-for-service program. N Engl J Med. 2009;360: 1418-28.

5. Coleman EA, Berenson RA. Lost in transition: challenges and opportunities for improving the quality of transitional care. Ann Intern Med. 2004; 141:533-6.

6. Jack BW, Chetty VK, Anthony D, et al. A reengineered hospital discharge program to decrease rehospitalization: a randomized trial. Ann Intern Med. 2009; 150:178-87.

7. Coleman EA, Parry C, Chalmers S, Min SJ. The care transitions intervention: results of a randomized controlled trial. Arch Intern Med. 2006; 166:1822-8.

8. Holland DE, Hemann MA. Standardizing hospital discharge planning at the Mayo Clinic. Jt Comm J Qual Patient Saf. 2011;37:29-36.

9. McCarthy D, Johnson MB, Audet AM. Recasting readmissions by placing the hospital role in community context. JAMA. 2013;309:351-2.

10. Hansen LO, Greenwald JL, Budnitz T, et al. Project BOOST: effectiveness of a multihospital effort to reduce rehospitalization. J Hosp Med. 2013;8:421-7.

11. Bradley EH, Sipsma H, Curry L, Mehrotra D, Horwitz LI, Krumholz H. Quality collaboratives and campaigns to reduce readmissions: what strategies are hospitals using? J Hosp Med. 2013;8:601-8.

12. Connolly M, Grimshaw J, Dodd M, et al. Systems and people under pressure: the discharge process in an acute hospital. J Clin Nurs. 2009; 18:549-58. 
13. Conn LG, Lingard L, Reeves S, Miller KL, Russell A, Zwarenstein M. Communication channels in general internal medicine: a description of baseline patterns for improved interprofessional collaboration. Qual Health Res. 2009;19:943-53.

14. Rhudy LM, Holland DE, Bowles KH. Illuminating hospital discharge planning: staff nurse decision making. Appl Nurs Res. 2010;23:198-206.

15. Zinn C. 14,000 preventable deaths in Australian hospitals. BMJ. 1995;310(6993): 1487.

16. Poor communication is common cause of errors. Healthcare Benchmarks Qual Improv. 2002;1:18-9.

17. Keating NL, Ayanian JZ, Cleary PD, Marsden PV. Factors affecting influential discussions among physicians: a social network analysis of a primary care practice. J Gen Intern Med. 2007;22:794-8.

18. Wu RC, Lo V, Rossos P, et al. Improving hospital care and collaborative communications for the 21st century: key recommendations for general internal medicine. Interact $\mathrm{J}$ Med Res. 2012;1:e9.

19. Gonzalo JD JY, Stuckey H, Fischer C, Sanchez L, Herzig S. Patient Care Transitions from the Emergency Department to the Medicine Ward: Evaluation of a Standardized Electronic Signout Tool. International Journal for Quality in Health Care. 2014;26(4):337-347.

20. Connolly M, Deaton C, Dodd $\mathbf{M}$, et al. Discharge preparation: do healthcare professionals differ in their opinions? J Interprof Care. 2010;24:633-43.

21. Koh HK, Brach C, Harris LM, Parchman ML. A proposed "health literate care model' would constitute a systems approach to improving patients' engagement in care. Health Aff (Millwood). 2013;32:357-67.

22. Brach C, Dreyer BP, Schillinger D. Physicians' roles in creating health literate organizations: a call to action. J Gen Intern Med. 2014;29:273-5.

23. Card SE, Ward HA, Chipperfield D, Sheppard MS. Postgraduate internal medicine residents' roles at patient discharge - do their perceived roles and perceptions by other health care providers correlate? J Interprof Care. 2014;28:76-8.

24. Hansen DL, Schneiderman B, Smith MA. Analyzing social media networks with NodeXL : insights from a connected world. Burlington: Morgan Kaufmann; 2011

25. Cott C. "We decide, you carry it out": a social network analysis of multidisciplinary long-term care teams. Soc Sci Med. 1997;45:1411-21.

26. Blau JR, Alba RD. Empowering nets of participation. Adm Sci Q 1982;27:363-79.

27. Scott J. Social Network Analysis. 3rd ed. Los Angeles: Sage; 2013.

28. Hawe $\mathbf{P}$, Webster $\mathbf{C}$, Shiell A. A glossary of terms for navigating the field of social network analysis. J Epidemiol Community Health. 2004;58:971-5.

29. Gonzalo JD, Wolpaw DR, Lehman E, Chuang $\mathbf{C H}$. Patient-centered interprofessional collaborative care: factors associated with bedside interprofessional rounds. J Gen Intern Med. 2014;29:1040-7.

30. Patton MQ. Qualitative research and evaluation methods. 3rd ed. Thousand Oaks: Sage Publications; 2002

31. Zwarenstein M, Goldman J, Reeves S. Interprofessional collaboration: effects of practice-based interventions on professional practice and healthcare outcomes. Cochrane Database Syst Rev. 2009;3:CD000072.

32. Institute of Medicine (U.S.) Committee on Guality of Health Care in America. Crossing the quality chasm : a new health system for the 21st century. Washington: National Academy Press; 2001.
33. Butcher L. Teamswork! Hosp Health Netw. 2012;86:24-7.

34. Weinstein RS, Brandt BF, Gilbert JH, Schmitt MH. Bridging the quality chasm: interprofessional teams to the rescue? Am J Med. 2013;126:276-7.

35. Schmitt MH, Gilbert JH, Brandt BF, Weinstein RS. The coming of age for interprofessional education and practice. Am J Med. 2013;126:284-8.

36. Foundation. JMJ. Transforming Patient Care: Aligning Interprofessional Education and Clinical Practice Redesign.; 2013; Atlanta, GA.

37. Satterfield JM, Bereknyei S, Hilton JF, et al. The Prevalence of Social and Behavioral Topics and Related Educational Opportunities During Attending Rounds. Acad Med. 2014;89(11):1548-1557.

38. Gittell JH. Coordinating mechanisms in care provider groups: Relational coordination as a mediator and input uncertainty as a moderator of performance effects. Management Science. 2002;48:1408-26.

39. O'Leary KJ, Ritter CD, Wheeler H, Szekendi MK, Brinton TS, Williams MV. Teamwork on inpatient medical units: assessing attitudes and barriers. Qual Saf Health Care. 2010;19:117-121.

40. O'Leary KJ, Thompson JA, Landler MP, et al. Patterns of nursephysician communication and agreement on the plan of care. Qual Saf Health Care. 2010;19:195-9.

41. Berkman ND, Sheridan SL, Donahue KE, Halpern DJ, Crotty K. Low health literacy and health outcomes: an updated systematic review. Ann Intern Med. 2011;155:97-107.

42. Chaudhry SI, Lien C, Ehrlich J, et al. Curricular Content of Internal Medicine Residency Programs: A Nationwide Report. Am J Med. 2014; 127(12): 1247-54.

43. Lifelong Learning - Physician Competency Development. American Hospital Association Physician Leadership Forum. 2014;2014 (August 19).

44. Duffy BL, Gonzalo J, Bost J, McNeil M. Improving Communication Skills and Transitions of Care: Development of a Discharge Summary Curriculum for Internal Medicine Interns. J Gen Intern Med. 2011;26:S614-S615.

45. Axon RN, Penney FT, Kyle TR, et al. A hospital discharge summary quality improvement program featuring individual and team-based feedback and academic detailing. Am J Med Sci. 2014;347:472-7.

46. ten Cate $\mathbf{O}$. Trust, competence, and the supervisor's role in postgraduate training. BMJ. 2006;333(7571):748-51.

47. Wynia MK, Von Kohorn I, Mitchell PH. Challenges at the intersection of team-based and patient-centered health care: insights from an IOM working group. JAMA. 2012;308:1327-8

48. Gittell $\mathbf{J H}$, Fairfield KM, Bierbaum B, et al. Impact of relational coordination on quality of care, postoperative pain and functioning, and length of stay - A nine-hospital study of surgical patients. Medical Care. 2000;38:807-19.

49. Stickrath C, Noble M, Prochazka A, et al. Attending Rounds in the Current Era: What Is and Is Not Happening. JAMA Intern Med. 2013;173(12): 1084-1089.

50. Gonzalo JD, Heist BS, Duffy BL, et al. The Art of Bedside Rounds: A Multi-Center Qualitative Study of Strategies Used by Experienced Bedside Teachers. J Gen Intern Med. 2012;28(3):412-420.

51. Beach C, Cheung DS, Apker J, et al. Improving Interunit Transitions of Care Between Emergency Physicians and Hospital Medicine Physicians: A Conceptual Approach. Acad Emerg Med. 2012;19:1188-95. 